\title{
Role of 10000-fold Effect in Improving Leg Cramps in Myelopathic Spinal Cord Changes - A Case Study
}

\author{
Vinod Kumar Tewari ${ }^{1 *}$, Neeraj Seth ${ }^{2}$, Devesh Johari ${ }^{3}$ and Lori Tewari ${ }^{4}$ \\ ${ }^{1}$ Neurosurgeon, Director, Advance Neuro and General Hospital, Lucknow, India \\ ${ }^{2}$ Physiotherapist, Advance Neuro and General Hospital, Lucknow, India \\ ${ }^{3}$ Opthalmologist, Jodhpur, Rajasthan, India \\ ${ }^{4}$ Advance Neuro and General Hospital, Lucknow, India \\ *Corresponding Author: Vinod Kumar Tewari, Neurosurgeon, Director, Advance \\ Neuro and General Hospital, Lucknow, India.
}

Received: October 09, 2020

Published: December 14, 2020

(C) All rights are reserved by Vinod Kumar

Tewari., et al.

\begin{abstract}
Leg muscle cramps in cervical myelopathic changes is inconsistent symptom and later on very disturbing to the patient specially in night time while taking rest.

NO is generated by nitric oxide synthase (NOS) which acts via 10000-fold effect to reverse the neuronal damage.

We have used intrathecal sodium nitroprusside to activate the 10000 -fold effect to modulate the retrograde neuroregulation in muscle cramps in cervical myelopathy in a case.
\end{abstract}

Keywords: Night Muscle Cramps; 10000-fold Effect; Intrathecal Sodium Nitroprusside

\section{Introduction}

Leg muscle cramps in cervical myelopathic changes is inconsistent symptom and later on very disturbing to the patient specially in night time while rest. The specific myelopathic changes along with mild gliosis causes false localising pain in lower limbs specially if added with cramps at night with rest [1].

Nitric oxide donors, like Sodium nitroprusside, modulates the antegrade neurotransmission via retrograde neuroregulation by 10000 -fold effect, is well established by the previous authors [2]. In myelopathic changes and subsequent leg muscle cramps at night, the insufficient glutamate transport induced motor neuronal gradual death ${ }^{2}$ hypothesised by us that the 10000 -fold effect could be one of the possible treatments in these life disturbing and painful conditions. The SNP causes release of NOS and then NO which causes 10000 -fold effect which modulates the ANT via RNT [2]. Previous authors also postulated the negative effect of NO but those authors had skipped the fact that the SOD (Superoxide Dismutase) and nNOS (neuronal Nitric Oxide Synthase) remains active at synaptic cleft for just 5 to 7 days [3].
We report one case of cervical cord non compressive myelopathic changes in cervical spinal cord, which presented with muscle cramps at night during rest.

We have utilised this ITSNP to induce 10000 -fold effect after $5^{\text {th }}$ day of diagnosis and after skipping the effect of SOD and nNOS. To quantify the effects, we have utilised AL-TENS (acupuncture like trans epidermal neural stimulation) in pre ITSNP and post ITSNP phase [4].

\section{Case Report}

A 32-year-old female presented in normal sensorium in OPD room with chief complaints of back of neck pain for 2 months then bilateral calf muscle night rest cramps from 1.5 months. No history of corona contact, tuberculosis or diabetes. On examination she has full GCS E54V5M6 (GLASGOW COMA SCALE), cranial nerves examination revealed normal. Motor examination showed left Hoffman was positive, right Hoffman was negative, superficial reflexes rest all the superficial and deep tendon reflexes are normal. ASIA grading done in motor, sensory and bladder bowel involvement which 
all were normal. Motor, normal nutrition of upper limbs and lower limbs both sides with tone and all reflexes. Sensory examination is showing 224/224 (all over body normal) without bladder bowel involvement.

MRI of cervical spine showed myelopathic changes with MRI of brain normal without any significant findings in rest of the cranial spinal axis (Figure 1, 2, 3 and 4).

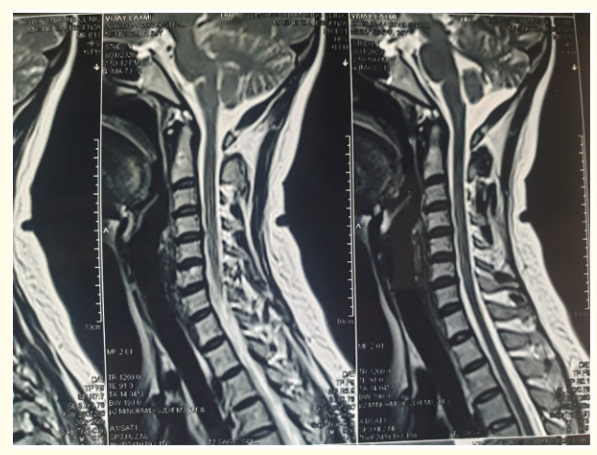

Figure 1

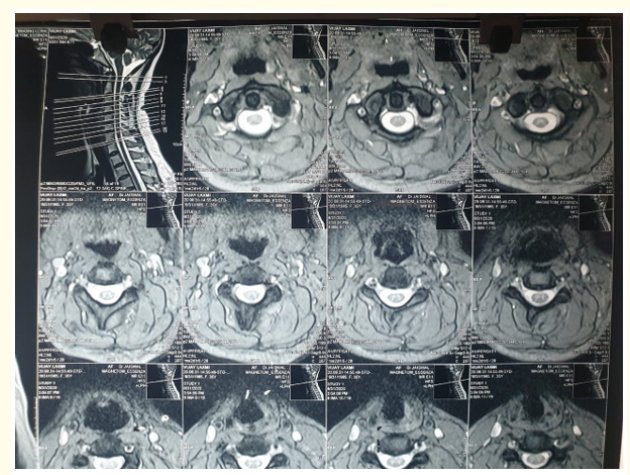

Figure 2

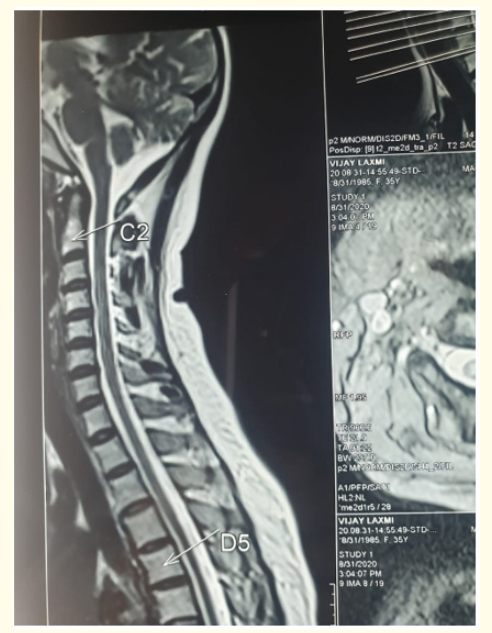

Figure 3

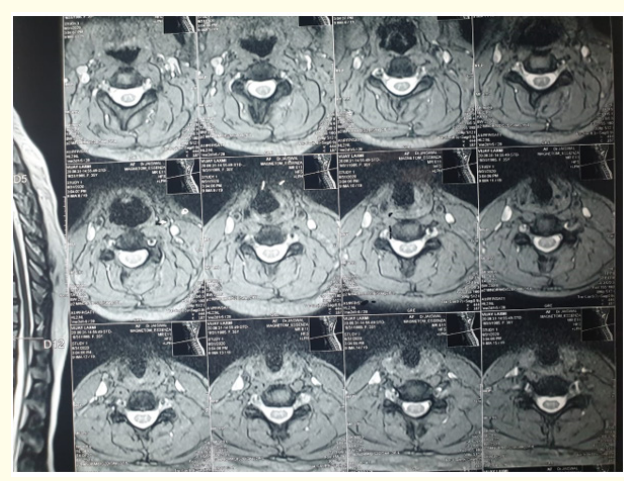

Figure 4

AL-TENS has been done which showed normal on all limbs.

After well informed consent and telling all untoward action (like sweating and apprehension) of ITSNP we superfused ITSNP about $15 \mathrm{ml}$ of the SNP given of $50 \mathrm{mg}$ of SNP dissolved in $200 \mathrm{ml}$ of Dextrose $5 \%$ solution with full photoprotection and freshly prepared. Post ITSNP AL-TENS done again after 2 hours, 24 hours, $7^{\text {th }}$ day and 14 th day and video recordings done.

Patient didn't have any muscle cramps since the day of ITSNP until now (2 months).

\section{Discussion}

The non-compressive myelopathic changes in cervical spinal cord causes vague symptoms from funicular pain [1] to muscle atrophy and cramps. Mostly affects due to unknown aetiology but a proposed mechanism of non-compressive myelopathic changes in cervical spinal cord pathophysiology is dynamic factors (such as hypermobility causing repetitive trauma) and the vascular aspect of the spinal cord plays an important role in the pathophysiology of CSM. Considerable evidence exists to support ischaemia as a major underlying pathologic event contributing to myelopathy. Anterior compression compromises perfusion through the transverse arterioles arising from the anterior sulcal arteries, while posterior cord compression compromises perfusion through the intramedullary branches of the central gray matter [5]. Oligodendrocytes, cells responsible for myelination of axons, respond poorly to ischaemia and this may explain the demyelination that occurs with chronic cervical myelopathy $[6,7]$. In the cervical spine, certain patients are more predisposed to myelopathy due to a congenitally narrowed spine cervical canal. The main pathology at synapse is via insufficient glutamate transport induced motor neuronal gradual death ${ }^{2}$ due to repeated dynamic injury specially flexion and extension. The NOD releases NO which causes modulation of ANT via RNT by 10000 -fold effect, thus increases the ANT impulses in those defective synaptic portions by bypassing the routine ANT impulses $[2,3]$. 
Previous authors have proposed a negative remark in the use of NOD that the NO will produce a negative effect just like double edged sword [2]. But from our work [3] it was well proved that the SOD level and nNOS level comes to normal after 5 to 7 days and if we skip this time the 10000 -fold effect comes to action to generate the ANT via RNT.

After ITSNP the patient felt better up to now that is 2 months and not a single episode of muscle cramps are noted by the patients.

\section{Conclusion}

This case was well diagnosed as MND and after giving ITSNP to induce the 10000 -fold effect got $75 \%$ improvement on $15^{\text {th }}$ day of post ITSNP phase.

\section{Bibliography}

1. Chee K Chan., et al. "Cervical cord compression presenting with sciatica-like leg pain". European Spine Journal 20 (2011): 217-221.

2. Tewari VK., et al. "The 10,000-Fold-Effect-Retrograde Neurotransmission- A Newer Concept for Paraplegias Physiological Revival-Use of Intrathecal Sodium Nitroprusside". Journal of Evolution of Medical and Dental Sciences 3.26 (2014): 72707285 .

3. Vinod Kumar Tewari., et al. "Intracarotid Sodium Nitroprusside on Fifth Post Ischemic Stroke Day in Middle Cerebral Artery Occlusion Rat Model". Journal of Clinical and Diagnostic Research 11.8 (2017): AF01-AF04.

4. Tewari VK., et al. "Acupuncture-like TENS (AL-TENS) as a Quantitative Measure for the Feasibility of Intrathecal Sodium Nitroprusside Superfusion in Paraplegics for Physiological Recovery-A Pilot Study (13 Cases)". Journal of Spinal Surgery 6.2 (2019): 44-48.

5. Hashizume Y., et al. "Pathology of spinal cord lesions caused by ossification of the posterior longitudinal ligament". Acta Neuropathology 63 (1984): 123-130.

6. Crowe MJ., et al. "Apoptosis and delayed degeneration after spinal cord injury in rats and monkeys". Nature Medicine 3 (1997): 3-76.

7. Keirstead HS and Blakemore WF. "The role of oligodendrocytes and oligodendrocyte progenitors in CNS remyelination". Advances in Experimental Medicine and Biology 468 (1999): 183-197.

\section{Assets from publication with us}

- Prompt Acknowledgement after receiving the article

- Thorough Double blinded peer review

- Rapid Publication

- Issue of Publication Certificate

- High visibility of your Published work

Website: www.actascientific.com/

Submit Article: www.actascientific.com/submission.php Email us: editor@actascientific.com

Contact us: +919182824667 